\title{
One economist's view of social medicine
}

\author{
ALAN WILLIAMS \\ From the Department of Economics, University of York
}

The rules of the game I was invited to play were that the Society for Social Medicine would provide me with reading material representative of their field and I was to comment on it as I thought fit, giving particular attention to how I saw economics, and economists, relating to it. This material included papers on epidemiology, medical statistics, social administration, and an unexpectedly large proportion of medical sociology.

\section{THE BUREAUCRACY OF SCIENCE}

In principle knowledge is doubtless indivisible, but in practice we have to divide it into small finite tracts, with plenty of overlap, in which each of us cultivates his respective plot with whatever tools he is most adept at using. It is inevitably a messy business, but as with all bureaucratic arrangements for the division of labour, it is occasionally rewarding to try to think through (and, if necessary, invent) the rationale of the system as we observe it, if only to reassure ourselves that there is no obviously better way of organising our activities. Sometimes such a review will prove more constructive than this, and indicate some rearrangement which offers the promise of more productive collaboration. It was in this spirit that I set about preparing this paper.

In thinking about my own subject I have found it useful to distinguish economics as an area of study from economics as a mode of thinking. By 'economics as an area of study' (or topic, for short) I mean essentially taking the economic system as the subject to be investigated, the presumption being that economists have special expertise on this particular topic. This 'special expertise' accumulates because by sustained thinking over several centuries about how different economic systems work and develop it proves useful to use certain concepts and structural relationships, to ask certain questions, and to collect certain data, all of which come to constitute the corpus of knowledge transmitted from one generation of investigators to the next, with increasing specialisation and internal subdivision of expertise as that corpus grows in volume and complexity. The 'special expertise' itself is what I call the 'mode of thinking', or discipline characteristic of the subject.
But although the relationship of the discipline of economics to the topic of economics may be a special and dominant one, it is not an exclusive one. It is not exclusive in two respects: firstly, the topic may be investigated by other disciplines, and secondly, this discipline may be used to investigate other topics. Let me illustrate each case in turn.

The topic of inflation is clearly within the ambit of economics, and it is one on which the discipline of economics is much utilised. But it is also very enlightening and fruitful to see inflation as a political or sociological or moral problem, and to apply the special expertise of those subjects to its analysis and clarification. In other words economic topics are not the exclusive preserve of one discipline, not even of the discipline with a special, and perhaps dominant, relationship to them.

Conversely, the discipline of economics will have something to contribute to topics which are not conventionally classified as 'economic' problems, for example, whether or not particular types of crime should attract the penalty of imprisonment or be tried by jury, how stringent fire and other safety regulations should be, or how many doctors we need. In other words, the discipline of economics is not exclusively focused on economic topics.

Turning to the topic of social medicine, I was initially intimidated (and I am not easily intimidated!) by the confusing array of elements which it appeared to embrace. I have already mentioned administration, epidemiology, sociology, and statistics, but in the assigned reading $I$ also found mention of behavioural studies, medicine, planning, and public health. In my supplementary, nonassigned reading $I$ also noted passing references to economics and operational research, although these appeared more peripheral and eccentric interests of particular individuals rather than part of the mainstream literature.

After considerable cogitation and several false starts, my provisional conclusion is that 'social medicine' is a topic but not a discipline. I say this with some trepidation. The trepidation is due partly to the fact that this may be interpreted as hostile comment, which it is not intended to be, and partly to the fact that at least one distinguished writer on the subject (Martin, 1977), who knows a lot more 
about all this than I do, clearly believes that it certainly is a discipline, and so terms it. I will nevertheless develop the argument that led me to my conclusion, for we shall then have a sporting chance of identifying the precise source of error, if error there be.

\section{WHAT IS SOCIAL MEDICINE?}

If I am right in assuming that the labels 'social medicine' and 'community medicine' are interchangeable, then the clearest and most concise delineation of the scope of the subject appears to be 'the speciality which evolved from public health and which covers the organisation and evaluation of health care systems and the medical aspects of the administration of health services'. (Holland, 1977). In this formulation there can be no doubt that in my terms it is a topic, or rather a group of topics, and not a discipline. This view seems implicit also in the further comment by the same author that epidemiology is 'the basic science of community medicine' and 'the study of the causes and distribution of disease in populations rather than individuals'. Moreover, since, 'health is influenced to some extent by the availability and usage of health services, epidemiology must also involve itself in the measurement of need and demand for, and use of, health care'. (Holland, 1977). In my terms, the crux of these assertions is that epidemiology is the discipline with the special, and perhaps dominant, relationship to the topic of social (or community) medicine.

Historically there is little cause to doubt this statement, but one could nevertheless fruitfully ask whether this is, or should be, any longer the case. What are the alternative candidates? I think we have to go through the related subjects listed earlier one by one, and see what their respective claims might be.

Sociology, like economics, is both a topic (social structure and social relationships, and the evolution of social systems) and a discipline (a systematic mode of thinking which employs characteristic concepts such as role, social class, stigmatisation, etc; and studies their interrelationships). The topic of social medicine seems to overlap with the topic of sociology, in the sense that the health care system is itself part of the social system, and may need to be studied in that context. But this is a different point from the one to which I am currently addressing myself, which is whether the discipline of sociology is, or should be, replacing the discipline of epidemiology as the 'basic science of social medicine'. If ever an innocent bystander ventured into a minefield, here is a touching instance, but economists have never shrunk from rushing in where angels feared to tread!
As I see it, epidemiology developed out of medicine as doctors came to recognise that disease in individuals had important characteristics which could be identified only by looking at whole communities, and which could be dealt with only by intervening at 'community level'. Initially these causative factors were still disease-specific ('germs', viruses, bacteria, etc.) and could be related comfortably to the concepts, if not the practice, of 'orthodox' medicine, which have an essentially biological and/ or chemical basis. As mental illness came more to the fore, and its underlying aetiology relied less on 'organic' phenomena as sources of explanation, and still more recently, as psychosomatic and social elements came increasingly to be recognised as at least contributory factors in much 'ordinary' illness, so the claim of sociology (as opposed to biology and chemistry) to provide the underlying conceptual framework for epidemiological work within social medicine has grown in strength too. And I suspect it will continue to do so. Whether epidemiology itself will change so as to accommodate this change, or whether 'traditional' epidemiological methods will prove unhelpful in this venture, I would not wish to predict. But the challenge of sociology, as discipline, is not so much a challenge to epidemiolog as a challenge to the role of medicine-and, behing it, the role of biological and chemical sciences-is the field of social medicine. This is reflected, in a intriguing linguistic way, by the differing connotations and implications of the terms 'social medicine' and 'medical sociology'.

The relationship to social medicine of social administration, and indeed of public administration and management, is also a confusing one. Social administration is a topic, not a discipline, and in my view it is in this respect on a par with social medicine. It has tended to start from sociology and concentrate on social services, whereas social medicine has tended to start from medicine and concentrate on health services. For the same reasons as those set out in the preceding paragraph, the respective roles of health services and personal social services have become increasingly blurred, and the growth of professional demarcation disputes between practitioners in the two broad fields is a significant indicator of this uncertainty. In the long run, I $D$ suspect that 'social medicine' will be absorbed by 'social administration' because I believe that a N sociological perspective, rather than a medical perspective, will eventually come to predominate. This may not be as dramatic a prediction as it sounds, however, because (a) it is going to take a long time and (b) both medicine and social medicine will move 0 (indeed already are moving) in that direction in any $\overparen{\mathbb{D}}$ case, so that these sharply differentiated 'labels' will ? 
come to be attached to increasingly indistinguishable activities.

Operational research is a more awkward candidate because it is a discipline, not a topic. It is essentially about the use of mathematical models for simulation and optimisation of complex systems, so it does constitute a direct challenge to epidemiology, which claims to do much the same thing. This is especially evident if one accepts the view that epidemiology 'is based on the study of groups or populations; it implies nothing essentially medical (nor, specifically, anything to do with infections)'. (Meade, 1975). I see no solution but the fusion of epidemiological method and operational research, unless a convention about respective spheres of influence comes to be established.

On the rest of the candidates I will be briefer. 'Planning' seems to be an activity so diffuse that we could all be said to be interested in it, and since it is not a discipline but a topic, there is no more I wish to say about it. The term 'behavioural studies' seems to me to connote no more than an empirical orientation to a study, though I think it is also sometimes used as a portmanteau term to pull together psychology, sociology, organisation theory, and, among the broad-minded, sometimes even economics! Perhaps others can see that it has greater significance to my argument which I have missed.

\section{WHERE DOES ECONOMICS FIT?}

If economics is subjected to the same treatment as that meted out to other subjects in my potted survey of the place of social medicine in the bureaucracy of knowledge, then again we must distinguish between economics the topic and economics the discipline.

Dealing first with the topic of economics, the relationship of the economic system to health and to the health care system is itself a fascinating area of study on which economics as a discipline can obviously contribute alongside other disciplines. The study of that relationship would embrace investigations into such questions as: What effects does the industrial and occupational structure have upon the level and pattern of ill health? To what extent does the health care system raise productivity-for example, by reducing absence from work through sickness? To what extent does the general state of the economy impinge on the resources available for the development of health care? Similar issues arise within the health care system as soon as it is seen explicitly as a resource-allocation system. For example, what are the effects of different charging systems on 'consumer' behaviour? What are the effects of different remuneration systems on 'producer' behaviour? What are the effects of various methods of financial allocation and control on real resource allocation? These are all economic topics related to an area of social organisation and behaviour in which we economists have a common interest with social medicine, social administration, etc., and I do not detect any great tensions in collaborative work in these particular fields, where the relevance of the economist's expertise is generally acknowledged.

But tension is much more apparent when economics as a discipline stakes out a claim to say something on topics which are not seen by others to be economic topics. I will take two classic, and very important, examples: the measurement of 'need' and the measurement of 'outcome'.

\section{NEED}

In the field of 'Needology' I have, to my own satisfaction at least, sorted out once and for all everyone's confusions about need, demand, utilisation, etc. (Williams, 1974) and I do not propose here to rehearse that material yet again. The essential point is that need can be 'objective' only if we translate the assertion 'Individual $A$ needs Intervention $\mathbf{X}$ ' into 'If individual $\mathbf{A}$ had intervention $\mathbf{X}$ then, in everybody's opinion, individual A would be better off'. If true, this is an essentially factual statement. It does not imply that $\mathrm{A}$ should have $\mathrm{X}$, however, because we do not know who else 'needs' $X$, how much $X$ is immediately available, or what the priorities are between rival claimants for the resources needed to provide $X$ now and in the future. Thus, if statements about 'need' are to get us anywhere, they must be linked to or incorporate valuations of some kind. Once they do this, they are ripe for analysis by economists, because the discipline of economics is essentially about valuation (and not simply valuation in markets, although as a topic that has been, and still is, our predominant interest). So what we would want to do is to move away from 'need' as quickly as possible, and talk instead about relative valuation, or trade-offs, or, in more common parlance, priorities. And since it is even more unlikely that everyone will share the same views on priorities than it is that they will all agree that individual $\mathbf{A}$ will be better off with intervention $\mathbf{X}$, then we shall also have to face the questions 'whose priorities', and what will be the process by which different people's preferences are accommodated, or not accommodated, as the case may be? Since markets are one way of accommodating such diversity, we economists tend to compare non-market solutions with market solutions, if only as an analytical device to highlight differences in outcome about which higher-level value judgements will have to be made. 
So if it is true that in the middle of the 1960 s the study not only of the needs of the community for medical care, but also of the demand for and the actual provision of these services were clear candidates for the second expansion of epidemiology' (Florey et al., 1976), then I hope any future expansionist urges in that area will be conducted more circumspectly and in harness with economists, so that they can help formulate the problem in a more policy-relevant way, and also ensure that the appropriate information is collected.

\section{OUTCOME}

The measurement of outcome, or effectiveness, is another topic in which the essential element of valuation has too often been ignored. There is no need for me to remind readers of this journal of the limitations of mortality and morbidity data as measures of outcome, but I do not detect a great deal of activity in social medicine in developing valid, versatile, and operational health status indexes, although these seem to me to offer the only way forward in this difficult country. The most rigorous and fundamental work in this field in the United Kingdom is the product of a collaboration between a clinical psychiatrist and an operational researcher (Rosser and Watts, 1972; 1975); there are also some ambitious attempts at applying the general idea in at least one department of community medicine. $\mathrm{Be}$ that as it may, the valuation of outcomes at all levels is a much neglected field, and even the routine things that people do do are not worked through rigorously or developed properly as evaluative tools (but see Wright, 1974; Culyer, 1976). Any 'index' or 'point' scheme, or implicit 'weighing' of one thing against another, contains a statement about 'trade-offs' or 'priorities' at the margin, on which the discipline of economics can often shed considerable light. I think it is fairly important, therefore, that the potential contribution of economists to the measurement of outcome-in other words, the valuation of benefitsshould be recognised and acted upon more widely and urgently in the field of social medicine than it is at the moment.

\section{$\cos \mathrm{T}$}

My final point concerns costs, which I have left until the end on purpose, because there is an unfortunate tendency to treat economists as if they were just cost-accountants, and to limit their role accordingly. We must blame ourselves, in part at least, for the fact that we tend to get 'type cast' in this somewhat restricted role, because our initial point of entry into many policy discussions has been to pose the question 'but what will it cost'? This is an important question, which still needs to be asked and to be answered more often than it is. Far too much 'evaluation' (in social medicine and elsewhere) is rendered useless for policy purposes by failure to consider costs, even in a narrow financial sense. As I have indicated, however, there is more to economics than the calculation of costs. All valuation problems are grist to our mill, and there will often be alternative sources of valuation, and the alternative configurations of an activity, which need to be incorporated in a study at the design stage if economic analysis is to be anything more than a last-minute cosmetic face-lift to mislead people into thinking that a real cost-effectiveness or cost-benefit study has been done. If the discipline of economics is to be a productive analytical tool when applied to the topic of social medicine, it must be allowed some influence on how problems are formulated in that field.

\section{APOLOGIA}

I have operated at a rather rarefied level of methodological abstraction in this paper. No one reading it will get much help in thinking up a better RAWP formula for use at subregional level, or in estimating the costs of a district nurse, or in determining how many geriatric beds we need in Biggleswade. As I interpreted it, my brief in preparing the opening paper was to raise very general issues, in a fairly provocative way, so that the members of the Society for Social Medicine who are present would realise from the outset what an uphill task it is going to be to straighten out us economists, although some of my colleagues may be more malleable than I am.

Nevertheless, the following issues seem particularly relevant for interdisciplinary discussion:

1 What is the current balance of work within the field of social medicine between the various topics/disciplines I have listed?

2 Are all the significant topics/disciplines there, and, if not, which ones have I omitted?

3 How do you see the balance changing over the next 10 or 20 years?

4 Do you agree with my analysis of the interrelationships of the topics/disciplines other than economics?

5 Does the claim I have staked out for economics seem (a) clear and (b) acceptable?

6 Where do we go from here?

Reprints from Professor Alan Williams, Department of Economics, University of York, Heslington, York YO1 5DD. 


\section{References}

Culyer, A. J. (1976). Need and the National Health Service. Martin Robertson: London.

Florey, C. du V., Weddell, J. M., and Leeder, S. R. (1976). The epidemiologist's contribution to medical care planning and evaluation. Australian and New Zealand Journal of Medicine. 6, 74-78.

Holland, W. W. (1977). A general view. In Epidemiology and Health. Edited by W. W. Holland and S. Gilderdale. Henry Kimpton: London.

Martin, F. M. (1977). Social medicine and its contribution to social policy. Lancet, 2, 1336-1338.

Meade, T. (1975). Epidemiology, health, and health services. In Specialised Futures: Essays in honour of
George Godber. Nuffield Provincial Hospitals Trust: London.

Rosser, R., and Watts, V. (1972). The measurement of hospital output. International Journal of Epidemiology, 1, 361-368.

Rosser, R., and Watts, V. (1975). Disability-a clinical classification. New Law Journal, 125, 323-328.

Williams, A. (1974). 'Need' as a demand concept (with special reference to health). In Economic Policies and Social Goals. Edited by A. J. Culyer. Martin Robertson: London.

Wright, K. (1974). Alternative measures of the output of social programmes: The elderly. In Economic Policies and Social Goals. Edited by A. J. Culyer. Martin Robertson: London. 